\title{
Possible Potentiation by Certain Antioxidants of the Anti-Inflammatory Effects of Diclofenac in Rats
}

\author{
Samah S. Abbas, ${ }^{1}$ Mona F. Schaalan, ${ }^{2}$ Ashraf K. Bahgat, ${ }^{3}$ and Ezzeddin S. El-Denshary ${ }^{3}$ \\ ${ }^{1}$ Department of Pharmacology and Toxicology, Misr International University (MIU), Km 28, \\ Cairo-Ismailia Road, P.O. Box 1, Heliopolis, Cairo, Egypt \\ ${ }^{2}$ Department of Biochemistry, Faculty of Pharmacy, Misr International University (MIU), Km 28, Cairo-Ismailia Road, \\ P.O. Box 1, Heliopolis, Cairo, Egypt \\ ${ }^{3}$ Department of Pharmacology and Toxicology, Faculty of Pharmacy, Cairo University, Giza, Egypt \\ Correspondence should be addressed to Mona F. Schaalan; m.schaalan@gmail.com
}

Received 30 August 2013; Accepted 22 January 2014; Published 12 March 2014

Academic Editors: P. Campiglia, G. Iaccarino, M. Illario, and N. Montuori

Copyright (C) 2014 Samah S. Abbas et al. This is an open access article distributed under the Creative Commons Attribution License, which permits unrestricted use, distribution, and reproduction in any medium, provided the original work is properly cited.

In the present study, we investigated the potential beneficial impact of the addition of antioxidant supplements to diclofenac regimen in a model of carrageenan-induced paw. Rats were treated daily with antioxidants, that is, a-lipoic acid (50 mg/kg), selenium $(2.5 \mathrm{mg} / \mathrm{kg})$, vitamin C $(1 \mathrm{~g} / \mathrm{kg})$, vitamin E $(300 \mathrm{mg} / \mathrm{kg})$, or zinc $(25 \mathrm{mg} / \mathrm{kg})$ on seven successive days and then received a single treatment with diclofenac or saline before carrageenan was injected to induce paw inflammation. The results indicated that these combinations did not significantly affect the percentage inhibition of paw edema caused by diclofenac alone; however, some combination treatments ameliorated signs of concomitant oxidative stress (such as alterations in plasma malondialdehyde (MDA) levels, hemolysate reduced glutathione levels, and erythrocytic superoxide dismutase enzyme activities) imparted by diclofenac alone. In some cases, few tested antioxidants in combination with diclofenac resulted in increased plasma levels of interleukin(IL-) 6 and C-reactive protein (CRP). In conclusion, the results of these studies suggested to us that the added presence of natural antioxidants could be beneficial as standard anti-inflammatory therapeutics for a patient under diclofenac treatment, albeit that these effects do not appear to significantly build upon those that could be obtained from this common anti-inflammatory agent per se.

\section{Introduction}

During the last decade, great advances have been made for understanding the pathophysiology of inflammation and the involvement of reactive oxygen species (ROS) in its pathogenesis. Inflammation is a complex defense mechanism in which leukocytes migrate from the vasculature into damaged tissues to destroy the agents that can potentially cause tissue injury [1]. Millions of people all over the world are suffering from inflammatory disorders, making them use huge amounts of anti-inflammatory agents (i.e., diclofenac, a nonselective cyclooxygenase [COX] inhibitor) for many years in their lives. However, the serious side effects and the induced intolerance of the anti-inflammatory drugs have led to the search for methods in order to decrease their effective doses and improve their safety patterns.
A plethora of evidence has shown that overproduction of ROS occurs at sites of inflammation and this contributes to overall tissue damage. A subsequent oxidative stress (OS) predominates when production of ROS exceeds the capacity of cellular antioxidant defenses to remove these toxic species [2]. Due to their high reactivity, ROS are potentially causing damage to biomolecules such as DNA, lipids, and proteins. Thus, there is increasing interest in examining the potential benefits from providing patients antioxidants, such as $\alpha$ lipoic acid ( $\alpha$-LA), selenium (Se), Vitamin C (Vit C), Vitamin $\mathrm{E}$ (Vit E), and zinc ( $\mathrm{Zn}$ )-supplements, as "add-ons" to their diclofenac regimen.

Accordingly, the aim of this study was to investigate the ability of several vitamins and elements (commonly taken as food supplements) to reduce any deleterious side effects from diclofenac or to potentially bolster the desired effects from 
the drug. While our main interest was to screen the potential efficacy of these vitamins as stand-alone agents in place of diclofenac or as "add-ons" to diclofenac against an induced inflammation in situ, we also hoped to begin to define any potential mechanisms of action that these agents might utilize in bringing about the observed effects. This included analyses of effects of each agent alone/in combination with diclofenac on some key cytokines $\backslash$ inflammatory mediators (i.e., interleukin [IL]-6 and C-reactive protein [CRP]) released during an inflammatory event). While we focused on the potential for these agents to reduce any undesired toxicities from the chronic use of diclofenac, we were also mindful that these studies could provide information that would allow for an unintended benefit potentially allowing for a decrease in the effective dose of diclofenac needed by a patient and a subsequent decrease in the risk of development of adverse effects.

\section{Materials and Methods}

2.1. Animals. Male Sprague Dawley rats (National Research Center, Giza, Egypt) weighing 100-120 g were used in this study. Rats were housed in a room with controlled temperature $\left(18-22^{\circ} \mathrm{C}\right)$, humidity $(60 \pm 10 \%)$, and light/dark $(12 \mathrm{hr} / \mathrm{d})$ cycles for at least 1 week before being randomized into various experimental groups. Throughout the study, rats were provided ad libitum access to standard pellet chow (ElNasr chemical Co., Cairo, Egypt) and filtered water. All experiments were conducted in accordance with the principles and procedures outlined in the International Guide for the Care and Use of Laboratory Animals and were approved by the Ethics Committee of the Faculty of Pharmacy Cairo University.

2.2. Drugs. Diclofenac (Diclofenac K; Novartis, Cairo, Egypt) was dissolved in distilled water to a concentration that would assure that a rat would receive per os a dose of $5 \mathrm{mg}$ diclofenac/kg body weight. In these studies, the single diclofenac treatment occurred alone or in combination with (i.e., $2 \mathrm{hr}$ after the final of the 7 daily doses) the test antioxidants. $\alpha$-Lipoic acid ( $\alpha$-LA; EVA Pharma, Giza, Egypt; in normal saline) was delivered by intraperitoneal injection at a dose of $50 \mathrm{mg} \alpha$-LA/ $/ \mathrm{kg}$ [3]. Each daily per os delivery of sodium selenite (Sigma, St. Louis, $\mathrm{MO}$; in water) at $2.5 \mathrm{mg}$ sodium selenite/kg [4]; Vit C (ADWIC, Al Qalyubiyah, Egypt; in water) at $1 \mathrm{~g} / \mathrm{kg}$ [5], Vit E (MP Biomedicals, BasRhin, France; in olive oil) at $300 \mathrm{mg} / \mathrm{kg}$ [6], and zinc sulfate (ADWIC; in water) at $25 \mathrm{mg} \mathrm{ZnSO} 4 / \mathrm{kg}$ [7] was performed without anesthesia and with a delivery volume of $1 \mathrm{~mL} / \mathrm{rat}$. The diclofenac volume (alone or after the final antioxidant dosing) was $1 \mathrm{~mL} /$ rat as well.

2.3. Experimental Design. Rats were randomly divided into 12 groups ( $n=8 /$ group): a carrageenan control, rats given diclofenac and then carrageenan, rats given $\mathrm{Vit} \mathrm{C}, \mathrm{Zn}, \alpha-$ LA, Vit E, or Se daily for $7 \mathrm{~d}$ and then carrageenan, and rats given Vit $\mathrm{C}, \mathrm{Zn}, \alpha$-LA, Vit $\mathrm{E}$, or Se for $7 \mathrm{~d}$, followed by diclofenac and then carrageenan. In the combination studies, treatment with diclofenac was always $2 \mathrm{hr}$ after the final antioxidant/vehicle treatment; rats in the carrageenan-only and antioxidant-only groups received saline at this timepoint. The carrageenan injection was performed $2 \mathrm{hr}$ later (i.e., $4 \mathrm{hr}$ after the final daily administration with the test antioxidants (or vehicle)).

2.4. Induction of Inflammation. Rats were injected subcutaneously in the plantar side of their left hind paws with $0.05 \mathrm{~mL}$ of a $1 \%$ carrageenan solution. Footpad swelling was then assessed (by monitoring changes in pad thickness) using vernier calipers (Mitutoyo, Tokyo, Japan). Paw thickness was measured just before the injection and 1,2, 3, and $4 \mathrm{hr}$ after injection. Based on preliminary studies that showed that maximum paw thickness increase occurred at $\approx 3 \mathrm{hr}$ after injection of carrageenan; the values obtained at that timepoint were used here to calculate values of percentage inhibition of paw thickness increase.

2.5. Preparation of Blood Samples. Four hours after the carrageenan injection, $4 \mathrm{~mL}$ blood was collected from the retroorbital plexus into heparinized tubes. A $0.5 \mathrm{~mL}$ aliquot was immediately transferred to another heparinized tube for erythrocyte separation and for determination of superoxide dismutase (SOD) activity. A $100 \mu \mathrm{L}$ aliquot of the original blood was hemolyzed for determination of reduced glutathione (GSH) content. The remaining original blood was centrifuged $\left(3000 \mathrm{rpm}, 4^{\circ} \mathrm{C}, 15 \mathrm{~min}\right)$ to isolate plasma; this was stored at $-20^{\circ} \mathrm{C}$ for subsequent determinations of levels of malondialdehyde (MDA), C-reactive protein (CRP), and IL-6.

2.6. Erythrocyte Separation. The aliquot spared for determination of SOD activity was centrifuged $\left(3000 \mathrm{rpm}, 4^{\circ} \mathrm{C}\right.$, $15 \mathrm{~min}$ ); the precipitated $\mathrm{RBC}$ were washed with $3 \mathrm{~mL}$ cold saline and then centrifuged again at $3000 \mathrm{rpm}$ for $10 \mathrm{~min}$. After the supernatant was discarded, lysing of the RBC was performed by resuspension of the cells in $1.75 \mathrm{~mL}$ ice-cold distilled water and then vigorous shaking; the cells were then left to stand for $15 \mathrm{~min}$ at $4^{\circ} \mathrm{C}$. The resulting hemolysate was used for determination of SOD activity.

2.7. Determination of Plasma Lipid Peroxides (MDA), CRP, and IL-6, Erythrocyte Superoxide Dismutase (SOD) Activity, and Blood Reduced Glutathione (GSH) Levels. The determination of lipid peroxide levels (as reflected in amounts of measurable MDA) was done as prescribed before [8]. In brief, to $0.2 \mathrm{~mL}$ plasma, $1.2 \mathrm{~mL}$ of $1 \%(\mathrm{w} / \mathrm{v}) o$-phosphoric acid and $0.4 \mathrm{~mL}$ of $0.67 \%(\mathrm{w} / \mathrm{v})$ thiobarbituric acid were added and mixed, and then the mixture was heated for $45 \mathrm{~min}$ in a boiling water bath. After cooling, $1.6 \mathrm{~mL} \mathrm{n}$ butanol was added and the sample was mixed vigorously. The butanol layer was separated by centrifugation at $3000 \mathrm{rpm}$ for $15 \mathrm{~min}$. The absorbance of the pink product in the butanol fraction was then measured at 535 and $520 \mathrm{~nm}$ in a Shimadzu double beam spectrophotometer (UV-150-02); all samples were read against a blank processed in parallel containing $0.2 \mathrm{~mL}$ distilled water instead of sample. The difference in 
absorbance between the two readings (i.e., $\Delta A_{535-520}$ ) was taken as a reflection of the level of MDA $(\mathrm{nmol} / \mathrm{mL})$ in the sample.

The pyrogallol autoxidation method was adopted for determination of erythrocyte SOD activity [9]. In brief, from the previously separated hemolysate of erythrocytes, $250 \mu \mathrm{L}$ was mixed vigorously with $0.75 \mathrm{~mL}$ chloroform-ethanol mixture $(3: 5 \mathrm{v} / \mathrm{v})$ to precipitate hemoglobin in the sample. In a microcuvette, $1 \mathrm{~mL}$ Tris- $\mathrm{HCl}$ buffer $(\mathrm{pH} 8.2)$ was added to $30 \mu \mathrm{L}$ of $10 \mu \mathrm{M}$ pyrogallol solution and $100 \mu \mathrm{L}$ distilled water; the absorbance at $420 \mathrm{~nm}$ was then measured 30 and $90 \mathrm{sec}$ thereafter. The difference in absorbance $(\Delta A)$ was used to reflect the rate of pyrogallol autoxidation (in $1 \mathrm{~min}$ ) and was considered the experiment blank. The same procedure was then carried out using the prepared blood samples or standards containing SOD in the place of distilled water. The reduction or inhibition of rate of autoxidation in $1 \mathrm{~min}$ (compared to the blank) was used as an index of the SOD activity. The percentage change in pyrogallol autoxidation was calculated as follows: \% change in pyrogallol autoxidation $=100-100 \times\left(\Delta A_{T}\right.$ or $\left.S / \mathrm{min}\right) / \Delta A_{B} / \mathrm{min}$, where $\Delta A_{T} / \mathrm{min}=$ change in absorbance of the test sample in $1 \mathrm{~min} . \Delta A_{S} / \mathrm{min}=$ change in absorbance of the standard sample in $1 \mathrm{~min}$, and $\Delta A_{B} /$ min $=$ change in absorbance of the blank sample in $1 \mathrm{~min}$.

Hemoglobin $(\mathrm{Hb})$ was measured via the cyanomethemoglobin [10]. Hemoglobin in a sample aliquot $(20 \mu \mathrm{L})$ was converted to cyanomethemoglobin by addition of $5 \mathrm{~mL}$ Drabkin's reagent $(0.6 \mathrm{mM}$ potassium ferricyanide $\backslash 0.77 \mathrm{mM}$ potassium cyanide); absorbance of the cyanomethemoglobin was then monitored at $540 \mathrm{~nm}$. From these latter values, the concentration of $\mathrm{Hb}$ was calculated as follows: $\mathrm{Hb}$ concentration $=A_{\text {sample }} \times 36.77(\mathrm{~g} / \mathrm{dL})$, where $A_{\text {sample }}$ is sample absorbance at $540 \mathrm{~nm}$, and 36.77 is a unitless constant factor. Based on these values, the SOD activities were then reexpressed as (USOD/g Hb) in blood sample) according to the following equation: SOD activity in blood sample $(\mathrm{U} / \mathrm{g} \mathrm{Hb})=$ SOD conc. $(\mathrm{U} / \mathrm{mL}) / \mathrm{g} \mathrm{Hb}$ in sample.

GSH levels in blood were determined as prescribed before [11]. In brief, $1 \mathrm{~mL}$ of hemolysate $(0.1 \mathrm{~mL}$ original blood $+0.9 \mathrm{~mL}$ distilled water) was combined with $1.5 \mathrm{~mL}$ of a protein precipitating solution ( $1.67 \mathrm{~g} \mathrm{~m}$-phosphoric acid, $0.2 \mathrm{~g}$ EDTA, and $30 \mathrm{~g} \mathrm{NaCl}$ in $100 \mathrm{~mL}$ distilled water) and then placed at room temperature for $5 \mathrm{~min}$. The sample was then centrifuged (3000 rpm, $15 \mathrm{~min}$ ) and the resultant supernatant assayed for GSH, that is, $1 \mathrm{~mL}$ supernatant (or standard GSH solution) was combined with $4 \mathrm{~mL}$ of the phosphate

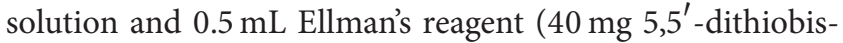
(2-nitrobenzoic acid) [DTNB] in $100 \mathrm{~mL} 1 \%$ sodium citrate solution). The absorbance of the resulting yellow solution was then measured at $412 \mathrm{~nm}$ (within $5 \mathrm{~min}$ ) in a spectrophotometer. From the absorbance values of standard GSH solutions, a standard curve was prepared and levels of GSH in each sample were then extrapolated ( $\mathrm{mg} \%$ ).

Plasma CRP and IL-6 levels were measured according to the procedures described in IMMULITE CRP and IL-6 assay kits, respectively (Diagnostic Product Corporation (DPC), Los Angeles, CA). The sensitivity of the CRP and IL-6 assay
TABLE 1: Effects of diclofenac, $\alpha$-LA, selenite, Vit C, Vit E, or zinc on paw thickness increase after $3 \mathrm{hr}$ in a rat carrageenan-induced paw edema model.

\begin{tabular}{lcc}
\hline Groups & $\begin{array}{c}\text { Paw edema (thickness } \\
\text { increase [cm] after 3 hr) }\end{array}$ & Inhibition \% \\
\hline $\begin{array}{l}\text { Carrageenan } \\
\text { (50 } \mu \text { L of 1\% solution) }\end{array}$ & $0.26 \pm 0.063$ & \\
Diclofenac & $0.16 \pm 0.001^{\#}$ & $38 \%$ \\
(5 mg/kg, per os) & $0.20 \pm 0.047^{\# \mathrm{a}}$ & $23 \%$ \\
$\alpha$-LA (50 mg/kg, IP) & $0.21 \pm 0.043^{\# \mathrm{a}}$ & $19 \%$ \\
$\mathrm{Se}(2.5 \mathrm{mg} / \mathrm{kg}$, po $)$ & $0.21 \pm 0.038^{\# \mathrm{a}}$ & $19 \%$ \\
$\mathrm{Vit} \mathrm{C}(1 \mathrm{~g} / \mathrm{kg}$, po $)$ & $0.18 \pm 0.031^{\# \mathrm{a}}$ & $31 \%$ \\
Vit E $(300 \mathrm{mg} / \mathrm{kg}$, po $)$ & $0.20 \pm 0.044^{\# \mathrm{a}}$ & $23 \%$ \\
$\mathrm{ZnSO}_{4}(25 \mathrm{mg} / \mathrm{kg}$, po $)$ &
\end{tabular}

Values are means of 8 rats $( \pm \mathrm{SD})$.

${ }^{\#}$ Value significantly different from carrageenan control $(P<0.05)$.

${ }^{\mathrm{a}}$ Value significantly different from diclofenac group $(P<0.05)$.

kits-defined as the concentration two standard deviations above the response at zero dose-was $\approx 1 \mathrm{pg} / \mathrm{mL}$.

2.8. Statistical Analysis. Values were expressed as mean \pm SD. Results were analyzed using one-way analysis of variance (ANOVA) followed by a least significant difference test (LSD) to compare between the different groups. A $P$ value $<0.05$ was accepted as significant in these tests. SPSS software (Chicago, IL) was used to carry out all analyses.

\section{Results}

3.1. Effects of Various Agents on the Rat Paw Edemas. Normal rats injected subcutaneously with carrageenan had an average $0.26 \mathrm{~cm}$ increase in paw thickness. Administration of diclofenac $2 \mathrm{hr}$ prior to the carrageenan markedly inhibited induced edema by $\approx 39 \%$; that is, increase in paw thickness was $0.16 \mathrm{~cm}$ (Table 1). Daily administration of $\alpha$-LA, Se, Vit $\mathrm{C}$, Vit $\mathrm{E}$, or $\mathrm{Zn}$ for $7 \mathrm{~d}$ prior to the injection of carrageenan significantly inhibited the induced paw edema by $23,19,19$, 31 , and $23 \%$, respectively (i.e., thickness values were $0.20,0.21$, $0.21,0.18$, and $0.20 \mathrm{~cm}$, resp.).

Administration of the following treatment combinations, diclofenac $+\alpha$-LA, diclofenac + Se, diclofenac + Vit C, diclofenac + Vit E, or diclofenac $+\mathrm{Zn}$, prior to injection of carrageenan markedly inhibited induced paw edema by 19 , $27,31,27$, and $46 \%$, respectively, relative to those in hosts that had received no drug treatment (i.e., Group I). Increases in paw thicknesses in these hosts were $0.21,0.19,0.18,0.19$, and $0.14 \mathrm{~cm}$, respectively (Table 2). The inhibitory effects imparted by the combinations were significantly no better than the diclofenac alone; only in the case of combination with $\mathrm{Zn}$ the inflammation was reduced better than the outcome induced by diclofenac alone.

3.2. Effects of Test Agents on Plasma MDA Levels. Injection of a $1 \%$ carrageenan solution into the paws of naive rats induced an oxidative stress reflected as a significant increase 
TABLE 2: Effects of combination treatments of diclofenac and the test antioxidants on paw thickness increase after $3 \mathrm{hr}$ in a rat carrageenan-induced paw edema model.

\begin{tabular}{lcc}
\hline Groups & $\begin{array}{c}\text { Paw edema } \\
\text { (thickness increase } \\
[\mathrm{cm}] \text { after } 3 \mathrm{hr})\end{array}$ & Inhibition \% \\
\hline $\begin{array}{l}\text { Carrageenan } \\
(50 \mu \mathrm{L} \text { of } 1 \% \text { solution })\end{array}$ & $0.26 \pm 0.06$ & $38 \%$ \\
\hline $\begin{array}{l}\text { Diclofenac } \\
(5 \mathrm{mg} / \mathrm{kg}, \text { per os })\end{array}$ & $0.16 \pm 0.001^{\#}$ & $19 \%$ \\
\hline $\begin{array}{l}\text { Diclofenac }+\alpha \text {-LA } \\
(50 \mathrm{mg} / \mathrm{kg}, \mathrm{IP})\end{array}$ & $0.21 \pm 0.001^{\# \mathrm{a}}$ & $27 \%$ \\
\hline $\begin{array}{l}\text { Diclofenac }+ \text { Se } \\
(2.5 \mathrm{mg} / \mathrm{kg}, \mathrm{po})\end{array}$ & $0.19 \pm 0.03^{\# \mathrm{a}}$ & $31 \%$ \\
\hline $\begin{array}{l}\text { Diclofenac }+ \text { Vit C } \\
(1 \mathrm{~g} / \mathrm{kg}, \mathrm{per} \text { os })\end{array}$ & $0.18 \pm 0.01^{\# \mathrm{a}}$ & $27 \%$ \\
\hline $\begin{array}{l}\text { Diclofenac }+ \text { Vit E } \\
(300 \mathrm{mg} / \mathrm{kg}, \text { po })\end{array}$ & $0.19 \pm 0.04^{\# \mathrm{a}}$ & $46 \%$ \\
\hline $\begin{array}{l}\text { Diclofenac }+\mathrm{Zn} \\
(25 \mathrm{mg} / \mathrm{kg}, \mathrm{po})\end{array}$ & $0.14 \pm 0.001^{\# \mathrm{a}}$ & \\
\hline
\end{tabular}

Values are means of 8 rats $( \pm S D)$.

${ }^{\#}$ Value is significantly different from carrageenan control $(P<0.05)$.

${ }^{a}$ Value is significantly different from diclofenac group $(P<0.05)$.

in plasma MDA; values in these rats were 2.77 -fold above background (Tables 3 and 4). Rats that received diclofenac $2 \mathrm{hr}$ before the carrageenan injection had a marked decrease in plasma MDA, that is, $56 \%$ relative to values in salinetreated carrageenan-injected rats. Daily injection of $\alpha$-LA for $7 \mathrm{~d}$ prior to the carrageenan also caused a significant decrease in plasma MDA levels (47.6\%) induced by the carrageenan itself. In rats that received a diclofenac $+\alpha$-LA combination, the decrease in MDA levels (relative to carrageenan-only rat levels) reached $69.4 \%$. Selenite administration for $7 \mathrm{~d}$ prior to induction of inflammation resulted in MDA levels being significantly lower (51.4\%) than those in nondrugtreated counterparts; in comparison, the diclofenac + selenite combination significantly decreased MDA levels by just $40.7 \%$. Treatment with Vit C for $7 \mathrm{~d}$ before induction of acute inflammation caused a significant $55.9 \%$ decrease in MDA levels; the diclofenac + Vit C combination significantly reduced (by 67.8\%) MDA levels to values approximating those in normal rats. Vit $\mathrm{E}$ given for $7 \mathrm{~d}$ prior to inflammation induction also resulted in a significant $67.8 \%$ decrease in plasma MDA levels compared to the level in the carrageenanonly rats. Unlike with Vit C, the diclofenac + Vit E treatment was less effective than the antioxidant alone; that is, the change compared to the inflamed rat values was now only $40.0 \%$. Lastly, dosing with $\mathrm{Zn}$ for $7 \mathrm{~d}$ before injection of carrageenan significantly decreased plasma levels of MDA $(43.0 \%)$ relative to that in the nondrug-treated hosts; in this case, the additional presence of diclofenac resulted in a $69.5 \%$ reduction in MDA values.

3.3. Effects of Test Agents on Hemolysate GSH Levels and Erythrocyte SOD Activity. Significant decreases in hemolysate GSH levels and erythrocyte (RBC) SOD activity (72 and $86 \%$, respectively, were noted in rats that received the carrageenan injection compared to values associated with the

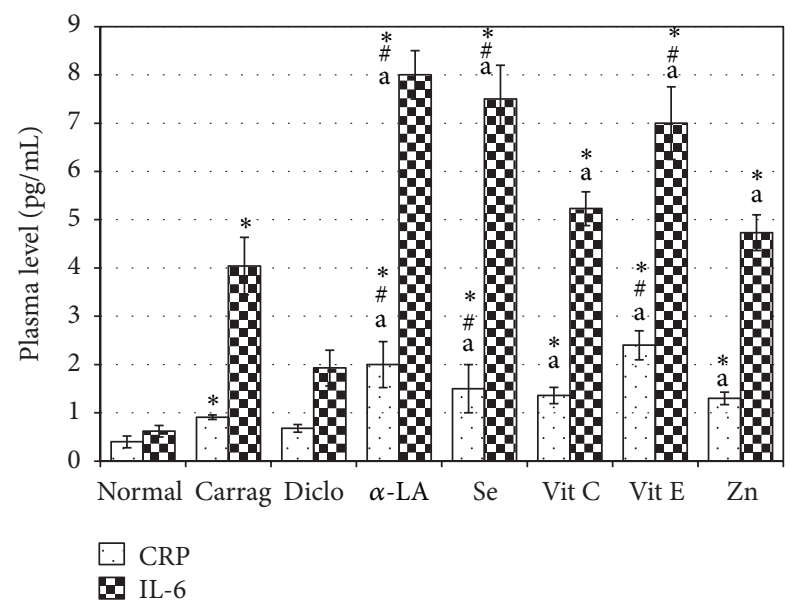

FIGURE 1: Effect of treatments on plasma CRP and IL-6 levels.All rats were provided daily oral doses of diclofenac $(5 \mathrm{mg} / \mathrm{kg})$, selenite $(2.5 \mathrm{mg} / \mathrm{kg})$, Vit C (1 g/kg), Vit E (300 mg/kg), or $\mathrm{ZnSO}_{4}(25 \mathrm{mg} / \mathrm{kg})$; $\alpha$-LA $(50 \mathrm{mg} / \mathrm{kg})$ was administered IP. ${ }^{* \#}$ Value is significantly different from normal control and carrageenan-only rats, respectively

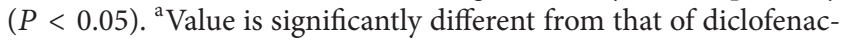
treated hosts $(P<0.05)$.

blood/cells of naïve [normal] rat) (Tables 3 and 4). Rats that received diclofenac $2 \mathrm{hr}$ before injection of carrageenan had GSH levels and SOD activity that were significantly greater (5.70- and 2.90-fold, resp.) compared to those in the saline-injected inflamed rats. The daily $\alpha$-LA regimen led to significant increases in the hemolysate GSH levels (2.15-fold versus control) and SOD activity (7.20-fold versus control) as well; the diclofenac $+\alpha$-LA combination led to significant increases in hemolysate GSH and RBC SOD of 3.95- and 2.44-fold, respectively. Selenite treatments prior to induction of inflammation resulted in significant increases in the GSH (2.17-fold) and SOD activity (4.00-fold) levels; the diclofenac + selenite regimen led to a significant increase in hemolysate GSH (3.99 fold) levels, but the change in RBC SOD activity was insignificant as compared to the values for the carrageenan-only rats. Treatments with Vit C or Vit E for $7 \mathrm{~d}$ before induction of inflammation, each caused significant increases in hemolysate GSH (3.00- and 2.43fold, resp.) and RBC SOD activity (4.75- and 2.60-fold, resp.) compared to values in the rats injected with carrageenan only. The additional presence of diclofenac resulted in significant increases in hemolysate GSH of $\approx 4$ - and 2.45-fold for Vit $\mathrm{C}$ and Vit E, respectively; RBC SOD activity was increased by $\approx 4$ - and 4.28-fold, respectively, as compared to levels in nondrug-treated inflamed rats. Lastly, $\mathrm{Zn}$ treatment prior to the carrageenan injection resulted in significant increases in hemolysate GSH levels ( $\approx 2$-fold) and RBC SOD activity (4fold) versus those in the carrageenan-only rats (Table 3 ). The diclofenac $+\mathrm{Zn}$ combination also led to significant increases in hemolysate GSH $(\approx 3$-fold $)$ and RBC SOD activities $(\approx 5$ fold).

3.4. Effects of Test Agents on Plasma CRP and IL-6 Levels. Levels of CRP and IL-6 in the plasma were also significantly increased (by 2.30- and 6.50-fold above naive level, resp.) 
TABLE 3: Effects of diclofenac, $\alpha$-LA, selenite, Vit C, Vit E, or zinc on plasma levels of MDA, hemolysate GSH, and erythrocyte SOD activity in a rat carrageenan-induced paw edema model.

\begin{tabular}{|c|c|c|c|}
\hline Groups & $\begin{array}{c}\text { MDA } \\
(\mathrm{nmol} / \mathrm{mL})\end{array}$ & $\begin{array}{c}\text { GSH } \\
(\mathrm{mg} \%)\end{array}$ & $\begin{array}{c}\text { SOD } \\
\text { (U/g Hb) }\end{array}$ \\
\hline Normal (50 $\mu \mathrm{L}$ saline) & $0.21 \pm 0.038$ & $2.03 \pm 0.21$ & $3.95 \pm 0.91$ \\
\hline Carrageenan ( $50 \mu \mathrm{L}$ of $1 \%$ solution) & $0.59 \pm 0.06^{*}$ & $0.55 \pm 0.26^{*}$ & $0.55 \pm 0.21^{*}$ \\
\hline Diclofenac ( $5 \mathrm{mg} / \mathrm{kg}$, per os) & $0.26 \pm 0.05^{\#}$ & $3.16 \pm 0.34^{* \#}$ & $1.61 \pm 0.16^{* \#}$ \\
\hline$\alpha$-LA (50 mg/kg, IP) & $0.31 \pm 0.09^{* \#}$ & $1.19 \pm 0.26^{* \# \mathrm{a}}$ & $3.93 \pm 0.87^{\# \mathrm{a}}$ \\
\hline $\mathrm{Se}(2.5 \mathrm{mg} / \mathrm{kg}, \mathrm{po})$ & $0.29 \pm 0.02^{* \#}$ & $1.59 \pm 0.12^{* \# \mathrm{a}}$ & $2.10 \pm 0.44^{* \# a}$ \\
\hline Vit C (1 g/kg, po) & $0.26 \pm 0.03^{\#}$ & $1.69 \pm 0.30^{* \# \mathrm{a}}$ & $2.59 \pm 0.32^{* \# \mathrm{a}}$ \\
\hline Vit E (300 mg/kg, po) & $0.19 \pm 0.03^{\# a}$ & $1.35 \pm 0.07^{* \# \mathrm{a}}$ & $1.44 \pm 0.25^{* \#}$ \\
\hline $\mathrm{ZnSO}_{4}(25 \mathrm{mg} / \mathrm{kg}, \mathrm{po})$ & $0.33 \pm 0.05^{* \# \mathrm{a}}$ & $1.20 \pm 0.16^{* \# \mathrm{a}}$ & $2.23 \pm 0.57^{* \# \mathrm{a}}$ \\
\hline
\end{tabular}

Values are means of 8 rats $( \pm \mathrm{SD})$.

${ }^{*}$ Value is significantly different from normal control $(P<0.05)$.

\#Value is significantly different from carrageenan control $(P<0.05)$.

${ }^{a}$ Value is significantly different from diclofenac group $(P<0.05)$.

TABLE 4: Effects of combination treatments of diclofenac and the test antioxidants on plasma levels of MDA, hemolysate GSH, and erythrocyte SOD activity in a rat carrageenan-induced paw edema model.

\begin{tabular}{|c|c|c|c|}
\hline Groups & $\begin{array}{c}\text { MDA } \\
(\mathrm{nmol} / \mathrm{mL})\end{array}$ & $\begin{array}{c}\text { GSH } \\
(\mathrm{mg} \%)\end{array}$ & $\begin{array}{c}\text { SOD } \\
(\mathrm{U} / \mathrm{g} \mathrm{Hb})\end{array}$ \\
\hline Normal (0.05 mL, $1 \%$ saline) & $0.21 \pm 0.05$ & $2.03 \pm 0.21$ & $3.95 \pm 0.91$ \\
\hline Carrageenan ( $50 \mu \mathrm{L}$ of $1 \%$ solution $)$ & $0.59 \pm 0.06^{*}$ & $0.55 \pm 0.26^{*}$ & $0.55 \pm 0.21^{*}$ \\
\hline Diclofenac $(5 \mathrm{mg} / \mathrm{kg}, \mathrm{po})$ & $0.26 \pm 0.048^{\#}$ & $3.16 \pm 0.34^{* \#}$ & $1.61 \pm 0.16^{* \#}$ \\
\hline Diclofenac $+\alpha$-LA $(50$ mg/kg, IP $)$ & $0.18 \pm 0.03^{\# \mathrm{a}}$ & $2.19 \pm 0.18^{\# \mathrm{a}}$ & $1.33 \pm 0.27^{* \#}$ \\
\hline Diclofenac + Se (2.5 mg/kg, po) & $0.35 \pm 0.08^{* \# \mathrm{a}}$ & $2.21 \pm 0.17^{* \# a}$ & $0.51 \pm 0.28^{* a}$ \\
\hline Diclofenac + Vit C (1 g/kg, po) & $0.19 \pm 0.02^{\# \mathrm{a}}$ & $2.20 \pm 0.30^{\# \mathrm{a}}$ & $2.12 \pm 0.55^{* \# a}$ \\
\hline Diclofenac + Vit E (300 mg/kg, po) & $0.36 \pm 0.09^{* \# \mathrm{a}}$ & $1.36 \pm 0.22^{* \# \mathrm{a}}$ & $2.33 \pm 0.39^{* \# \mathrm{a}}$ \\
\hline Diclofenac + Zn $(25$ mg/kg, po $)$ & $0.18 \pm 0.03^{\# \mathrm{a}}$ & $1.62 \pm 0.20^{* \# \mathrm{a}}$ & $2.65 \pm 0.21^{* \# \mathrm{a}}$ \\
\hline
\end{tabular}

Values are means of 8 rats $( \pm S D)$.

${ }^{*}$ Value is significantly different from normal control $(P<0.05)$.

"Value is significantly different from carrageenan control $(P<0.05)$.

${ }^{a}$ Value is significantly different from diclofenac group $(P<0.05)$.

as a result of carrageenan injection (Figures 1 [single agent treatments] and 2 [combination treatments]). Rats that received diclofenac $2 \mathrm{hr}$ before injection of carrageenan had insignificant decreases in the "now-elevated" plasma levels of CRP and IL-6 (25.27 and 52.35\% decrease, resp.) noted in the carrageenan-only-treated rats; interestingly, these latter levels were increased 2.30- and 6.50-fold, respectively, above naïve rat values. Daily $\alpha$-LA injections prior to the carrageenan caused a significant increase in plasma levels of CRP (5.0and 2.2-fold) and IL-6 (12.90- and 1.98-fold) compared to the levels in naive and carrageenan-only-treated rats, respectively (Figure 1). Rats that received the diclofenac + $\alpha$-LAcombination also had significant increases in plasma CRP (3.77- and 1.65 fold) and IL-6 (8.30- and 1.28-fold) levels compared, respectively, to levels in naive and carrageenanonly rats (Figure 2). Selenite treatments also caused significant increases in plasma CRP (3.75- and 1.50-fold) and IL-6 (12.00- and 1.86-fold) levels; the diclofenac + selenite combination resulted in slightly greater significant increases in CRP (5.00- and 2.20-fold) and IL-6 (10.50- and 1.60fold) levels. Vit C administration (alone or in combination with diclofenac) did not significantly affect plasma levels of CRP and IL-6 as compared to the levels in carrageenanonly rats. In contrast, Vit E given for $7 \mathrm{~d}$ prior to induction of inflammation resulted in significant increases in plasma CRP (6.00- and 2.60-fold) and IL-6 (12.00- and 1.86-fold) levels relative to levels in normal and carrageenan-only rats, respectively; the diclofenac + Vit E regimen caused slightly lower, albeit still significant, increases in CRP (5.5- and 2.4fold) and IL-6 (9.7- and 1.5-fold) levels. Administration of $\mathrm{Zn}$ (alone or in combination with diclofenac) before the carrageenan did not significantly affect plasma CRP and IL-6 levels relative to those in the inflamed nondrug-treated rats.

\section{Discussion}

Interest in the relationship between inflammation and oxidative stress has risen in recent years as they share a common role in the etiology of a variety of chronic diseases. Many of these disorders share a common pathophysiological link in terms of chronic low-grade inflammation and overproduction of reactive oxygen and nitrogen species (ROS and RON). 


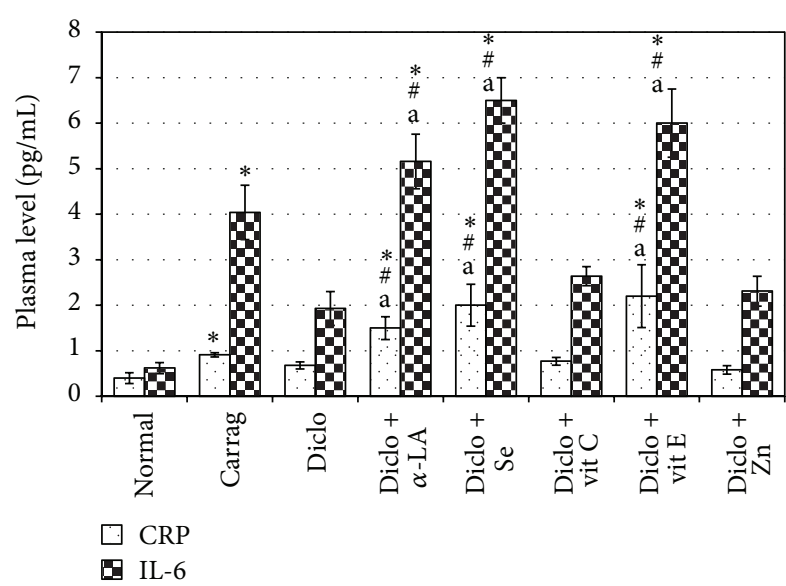

FIgURE 2: Effect of combinational treatments on plasma CRP and IL-6 levels. All rats were provided daily oral doses of diclofenac in combination with selenite, Vit C, Vit E, or $\mathrm{ZnSO}_{4}$; $\alpha$-LA $(50 \mathrm{mg} / \mathrm{kg})$ was administered IP. Doses were the same as outlined in Figure 1 legend. ${ }^{* \#}$ Value is significantly different from normal control and carrageenan-only rats, respectively $(P<0.05) .{ }^{\text {a } V a l u e ~ i s ~ s i g n i f i c a n t l y ~}$ different from that of diclofenac-treated hosts $(P<0.05)$.

Based on this, studies were initiated to investigate the efficacy of several antioxidants to potentially reduce inflammation and cytokine mediators that occur in a model of acute inflammation (i.e., carrageenan-induced rat paw edema) [2].

In the study here, treating the acutely inflamed rats with diclofenac caused a significant inhibition in paw thickness increases, a finding previously noted using an oral dose dissimilar to that here [12]. Another study also showed that diclofenac was effective in reducing paw edema in both irradiated and nonirradiated rats using celecoxib [13]. The assessment here of the anti-inflammatory efficacy of antioxidants $\alpha$-LA, Se, Vit C, Vit E, and Zn revealed a significant inhibition in paw thickness increases to different extents, that is, Vit E- $>\alpha$-LA, $\mathrm{Zn}>\mathrm{Se} \backslash$ Vit $\mathrm{C}$. In all cases, these agents (alone or in combination with diclofenac) yielded changes in thickness increases significantly no better than the diclofenac alone; only in the case of combination with $\mathrm{Zn}$ the inflammation was reduced better than the outcome induced by diclofenac alone. This finding gave us a pause as to the potential significance of use of these antioxidants as adjunctive therapeutics. However, on their own, these agents did induce significant reductions in paw thickness; as such, our interest in their potential use as stand-alone antiinflammatory agents remained intact.

Our findings with the antioxidants alone were in accordance with the study that investigated the anti-inflammatory effects of $\alpha$-LA in carrageenan-paw edema model [3] and another study, which showed that administration of Vit C reduced expected increases in hind paw inflammatory edema in a model of adjuvant-induced arthritis in rats [5]. AbouMohamed et al. concluded that $\mathrm{ZnSO} 4$ supplementation reduced carrageenan-paw edema in rats as well [7].

An association between oxidative stress and inflammatory responses induced by carrageenan in our study was reflected in significant increases in plasma levels of MDA and decreases in both hemolysate GSH levels and RBC SOD activities. Such outcomes are similar to those reported by other studies $[3,14]$. Another evidence indicated that diclofenac induced amelioration of elevated plasma MDA levels and increased the activity of total plasma SOD in a rat adjuvant arthritis model [15]. However, Khayyal et al. presented contrasting results; that is, diclofenac failed to alter plasma levels of MDA or affect GSH levels or SOD activity; it has been suggested that this contrasting outcome may be attributed to the small dose of diclofenac that these investigators used [13]. The antioxidant efficacy of the studied agents in terms of reduction of elevated MDA levels and elevation in both hemolysate GSH and erythrocyte SOD activity reiterates the findings of several previous studies [16-18]. Nevertheless, though the adjunctive therapy of the test agent with diclofenac failed to present any significant increased efficacy against changes in paw thickness edema measure, the findings still proved a significant promising in regard to antioxidant activity.

In general, plasma CRP levels correlate with severity of inflammatory disease or tissue injury [19]. In vitro studies have shown that control of this response is primarily regulated by IL-6 [20]. However, Jones et al. showed that the relationship between IL- 6 and CRP is more complex than previously thought, since IL-6R shedding in response to CRP likely contributes to the formation of an agonistic sIL-6R/IL6 complex [21]. Thus, CRP not only acts as an acute phase reactant but it also may have a profound effect on distal IL-6mediated events that occur during the inflammatory process. Indeed, CRP levels in several diseases have been found to correlate with those of sIL-6R [22].

The consensus that the increase in plasma CRP and IL6 levels correlates with severity of inflammatory disease was confirmed in the current study. Another study demonstrated an increase in IL-6 levels in blood $3 \mathrm{hr}$ after injection of carrageenan in a model of carrageenan-induced hyperalgesia. Such outcomes are suggestive of a possibility that circulating IL- 6 could act as a messenger of information from peripheral inflammatory sites to the CNS [23]. Furthermore, another study demonstrated that IL-6 serum levels were significantly increased at $24 \mathrm{hr}$ following edema induction, but not after $3 \mathrm{hr}$, in a model of carrageenan-induced rat paw edema [24]. However, contradictory results indicated that LPS-induced inflammatory paw edema in rats, but not the type induced by carrageenan, resulted in measurable levels of IL-6 in serum within $3 \mathrm{hr}$ of induction [25].

Oral administration of diclofenac here lowered the elevated plasma levels of CRP and IL-6, but the changes were not significant. Similarly, other investigators noted that circulating IL-6 levels remained unaffected after intraarterial or peritoneal injection of diclofenac [26]. Moreover, investigating the modulatory effects of diclofenac on IL-6 and prostaglandin (PG) levels showed that diclofenac significantly decreased PGE2 production but had no significant effect on IL-6 levels [27]. As the anti-inflammatory effect of diclofenac was reflected only in the inhibition of the paw thickness increase as compared to that in the untreated inflamed rats but not in the decreases in plasma IL-6, it could be concluded that the cytokine inhibition does not 
completely explain the efficacy of cyclooxygenase (COX) inhibitors (like diclofenac) in downregulating acute inflammation (i.e., suggesting another mechanism independent on COX inhibition). This observation appears to confirm earlier observations $[28,29]$.

To our best understanding, the study here was the first attempt to test the additive anti-inflammatory impact on the studied test agents on diclofenac through assessment of CRP and IL-6. Interestingly, $\alpha$-LA, Vit E, sodium selenite, and their combinations with diclofenac (contrary to with diclofenac monotherapy) caused significant increases in plasma levels of IL- 6 and CRP as compared to levels measured in normal rats as well as in carrageenan-only-treated rats. Such immunostimulatory effects of these antioxidants, in particular, Vit E, have been demonstrated previously $[30,31]$.

A plethora of evidence indicates that CRP also performs anti-inflammatory functions in situ [32-37]. Moreover, it has been documented that IL-6 exhibits two contrasting features; it acts as a proinflammatory cytokine in models of chronic inflammatory diseases, that is, collageninduced arthritis, murine colitis, or experimental autoimmune encephalomyelitis [38]. In contrast, in models of acute inflammation, IL-6 exhibits an anti-inflammatory profile [39]. It has also been reported that IL-6 is involved in Tcell activation and represents an essential competence factor that synergizes with IL-1 to control initial steps of T-cell activation, including induction of IL-2 and enhancement of responsiveness to IL-2 [40, 41]. As IL-2 production is dependent on the release of IL-6, and (of the agents tested here) Vit E supplementation increased IL-2 plasma levels $[30,31]$, this could explain the current interesting finding that Vit E caused a significant rise in plasma IL-6 levels in our inflamed hosts.

In conclusion, the results of the present study (when taken in the context of the above-noted studies) showed that the immunostimulatory effects of antioxidants, namely, $\alpha$-LA, Vit E, and selenite, might be related to an induced release of IL- 6 and subsequent induction of CRP release. The current results showed that the administration of other antioxidants, namely, Vit $\mathrm{C}, \mathrm{Zn}$, and their combinations with diclofenac, did not significantly affect plasma IL-6 and CRP levels. It is worth mentioning that the administration of diclofenac and $\alpha$-LA, Se, and Vit $\mathrm{E}$ caused significant increases in plasma CRP and IL-6 levels as compared to values seen in untreated carrageenan-only injected rats. However, these levels were lower than those caused by administration of the each antioxidant individually.

In summary, the combination of diclofenac and any of the anti-inflammatory agents tested here appears to preserve any immunomodulating effect of the antioxidant alone. Thus, we conclude that the addition of antioxidants to any treatment regimen using this particular drug could have potential beneficial effects for the patient under treatment, albeit that it is not one that builds upon the effects from the diclofenac perse.

The presented findings are complementary to the conclusion drawn from the previously published systematic review of Canter et al. on evidenced randomized clinical trials (RCTs) for the effectiveness of the antioxidant Vitamins A,
C, E, or selenium or their combination in the treatment of arthritis. Clinical trials testing the efficacy of Vitamin E in the treatment of arthritis have been methodologically weak and have produced contradictory findings. There is presently no convincing evidence that selenium, Vitamin A, Vitamin $\mathrm{C}$, or the combination product selenium ACE are effective in the treatment of any type of arthritis [42].

\section{Conflict of Interests}

The authors declare that there is no conflict of interests regarding the publication of this paper.

\section{References}

[1] C. Gabay, "Interleukin-6 and chronic inflammation," Arthritis Research and Therapy, vol. 8, supplement 2, article S3, 2006.

[2] J. M. Peake, K. Suzuki, and J. S. Coombes, "The influence of antioxidant supplementation on markers of inflammation and the relationship to oxidative stress after exercise," Journal of Nutritional Biochemistry, vol. 18, no. 6, pp. 357-371, 2007.

[3] N. A. El-Shitany, S. A. El-Masry, M. A. El-Ghareib, and K. ElDesoky, "Thioctic acid protects against carrageenan-induced acute inflammation in rats by reduction in oxidative stress, downregulation of COX-2 mRNA and enhancement of IL-10 mRNA," Fundamental and Clinical Pharmacology, vol. 24, no. 1, pp. 91-99, 2010.

[4] M. D. Deore, A. K. Srivastava, and S. K. Sharma, "Effect of reduced glutathione treatment on selenosis, blood selenium concentration and glutathione peroxidase activity after repeated short-term selenium exposure in buffalo calves," Toxicology, vol. 213, no. 1-2, pp. 169-174, 2005.

[5] A. Sakai, T. Hirano, R. Okazaki, N. Okimoto, K. Tanaka, and T. Nakamura, "Large-dose ascorbic acid administration suppresses the development of arthritis in adjuvant-injected rats," Archives of Orthopaedic and Trauma Surgery, vol. 119, no. 3-4, pp. 121-126, 1999.

[6] T. Y. Liu, C. C. Chen, C. L. Chen, and C. W. Chi, "Safroleinduced oxidative damage in the liver of Sprague-Dawley rats," Food and Chemical Toxicology, vol. 37, no. 7, pp. 697-702, 1999.

[7] G. Abou-Mohamed, H. A. El-Kashef, H. A. Salem, and M. M. Elmazar, "Effect of zinc an the anti-inflammatory and ulcerogenic activities of indometacin and diclofenac," Pharmacology, vol. 50, no. 4, pp. 266-272, 1995.

[8] M. Uchiyama and M. Mihara, "Determination of malonaldehyde precursor in tissues by thiobarbituric acid test," Analytical Biochemistry, vol. 86, no. 1, pp. 271-278, 1978.

[9] S. Marklund and G. Marklund, "Involvement of the superoxide anion radical in the autoxidation of pyrogallol and a convenient assay for superoxide dismutase," European Journal of Biochemistry, vol. 47, no. 3, pp. 469-474, 1974.

[10] "International Committee for Standardization in Haematology," British Journal of Haematology, vol. 13, pp. 68-70, 1967.

[11] E. Beutler, O. Duron, and B. M. Kelly, "Improved method for the determination of blood glutathione," The Journal of Laboratory and Clinical Medicine, vol. 61, pp. 882-888, 1963.

[12] F. Odabasoglu, Z. Halici, A. Cakir et al., "Beneficial effects of vegetable oils (corn, olive and sunflower oils) and $\alpha$ tocopherol on anti-inflammatory and gastrointestinal profiles of indomethacin in rats," European Journal of Pharmacology, vol. 591, no. 1-3, pp. 300-306, 2008. 
[13] M. T. Khayyal, M. A. El-Ghazaly, R. M. El-Hazek, and A. S. Nada, "The effects of celecoxib, a COX-2 selective inhibitor, on acute inflammation induced in irradiated rats," Inflammopharmacology, vol. 17, no. 5, pp. 255-266, 2009.

[14] J.-H. Shang, X.-H. Cai, T. Feng et al., "Pharmacological evaluation of Alstonia scholaris: anti-inflammatory and analgesic effects," Journal of Ethnopharmacology, vol. 129, no. 2, pp. 174181, 2010.

[15] N. Tastekin, N. Aydogdu, D. Dokmeci et al., "Protective effects of l-carnitine and alpha-lipoic acid in rats with adjuvant arthritis," Pharmacological Research, vol. 56, no. 4, pp. 303-310, 2007.

[16] A.-R. M. A. Meki, E. A. Hamed, and K. A. Ezam, "Effect of green tea extract and vitamin $\mathrm{C}$ on oxidant or antioxidant status of rheumatoid arthritis rat model," Indian Journal of Clinical Biochemistry, vol. 24, no. 3, pp. 280-287, 2009.

[17] D. M. Tessier, A. Khalil, L. Trottier, and T. Fülöp, "Effects of vitamin $C$ supplementation on antioxidants and lipid peroxidation markers in elderly subjects with type 2 diabetes," Archives of Gerontology and Geriatrics, vol. 48, no. 1, pp. 67-72, 2009.

[18] M. Gabrashanska, S. E. Teodorova, S. Petkova, L. Mihov, M. Anisimova, and D. Ivanov, "Selenium supplementation at low doses contributes to the antioxidant status in Trichinella spiralis-infected rats," Parasitology Research, vol. 106, no. 3, pp. 561-570, 2010.

[19] M. B. Pepys and M. L. Baltz, "Acute phase proteins with special reference to C-reactive protein and related proteins (pentaxins) and serum amyloid A protein," Advances in Immunology, vol. 34, pp. 141-212, 1983.

[20] A. J. Szalai, F. W. van Ginkel, S. A. Dalrymple, R. Murray, J. R. McGhee, and J. E. Volanakis, "Testosterone and IL-6 requirements for human $\mathrm{C}$-reactive protein gene expression in transgenic mice," Journal of Immunology, vol. 160, no. 11, pp. 5294-5299, 1998.

[21] S. A. Jones, D. Novick, S. Horiuchi, N. Yamamoto, A. J. Szalai, and G. M. Fuller, "C-reactive protein: a physiological activator of interleukin 6 receptor shedding," Journal of Experimental Medicine, vol. 189, no. 3, pp. 599-604, 1999.

[22] D. Kyriakou, H. Papadaki, A. G. Eliopoulos, A. Foudoulakis, M. Alexandrakis, and G. D. Eliopoulos, "Serum soluble IL6 receptor concentrations correlate with stages of multiple myeloma defined by serum $\beta 2$-microglobulin and C-reactive protein," International Journal of Hematology, vol. 66, no. 3, pp. 367-371, 1997.

[23] Y. Oka, T. Ibuki, K. Matsumura et al., "Interleukin-6 is a candidate molecule that transmits inflammatory information to the CNS," Neuroscience, vol. 145, no. 2, pp. 530-538, 2007.

[24] C. Cicala, S. Morello, A. Alfieri, V. Vellecco, S. Marzocco, and G. Autore, "Haemostatic imbalance following carrageenaninduced rat paw oedema," European Journal of Pharmacology, vol. 577, no. 1-3, pp. 156-161, 2007.

[25] B. N. L. Vajja, S. Juluri, M. Kumari, L. Kole, R. Chakrabarti, and V. D. Joshi, "Lipopolysaccharide-induced paw edema model for detection of cytokine modulating anti-inflammatory agents," International Immunopharmacology, vol. 4, no. 7, pp. 901-909, 2004.

[26] A. Greis, J. Murgott, S. Rafalzik, R. Gerstberger, T. Hübschle, and J. Roth, "Characterization of the febrile response induced by fibroblast-stimulating lipopeptide-1 in guinea pigs," American Journal of Physiology: Regulatory Integrative and Comparative Physiology, vol. 293, no. 1, pp. R152-R161, 2007.
[27] R. Cruz, J. D. Quintana-Hau, J. R. González, R. TorneroMontaño, L. M. Baiza-Durán, and L. Vega, "Effects of an ophthalmic formulation of meloxicam on COX-2 expression, PGE2 release, and cytokine expression in a model of acute ocular inflammation," British Journal of Ophthalmology, vol. 92, no. 1, pp. 120-125, 2008.

[28] J. L. Dugina, V. I. Petrov, A. R. Babayeva et al., "A randomized, open-label, comparative, 6-month trial of oral ultra-low doses of antibodies to tumor necrosis factor- $\alpha$ and diclofenac in rheumatoid arthritis," International Journal of Tissue Reactions, vol. 27, no. 1, pp. 15-21, 2005.

[29] J. A. Schleining, S. R. McClure, R. B. Evans, W. G. Hyde, L. W. Wulf, and A. J. Kind, "Liposome-based diclofenac for the treatment of inflammation in an acute synovitis model in horses," Journal of Veterinary Pharmacology and Therapeutics, vol. 31, no. 6, pp. 554-561, 2008.

[30] S. N. Han, D. Wu, W. K. Ha et al., "Vitamin E supplementation increases $\mathrm{T}$ helper 1 cytokine production in old mice infected with influenza virus," Immunology, vol. 100, no. 4, pp. 487-493, 2000.

[31] O. Adolfsson, B. T. Huber, and S. N. Meydani, "Vitamin Eenhanced IL-2 production in old mice: naive but not memory T cells show increased cell division cycling and IL-2-producing capacity," Journal of Immunology, vol. 167, no. 7, pp. 3809-3817, 2001.

[32] J. Filep and E. Foldes-Filep, "Effects of C-reactive protein on human neutrophil granulocytes challenged with $\mathrm{N}$-formylmethionyl-leucyl-phenylalanine and platelet-activating factor," Life Sciences, vol. 44, no. 8, pp. 517-524, 1989.

[33] R. R. Kew, T. M. Hyers, and R. O. Webster, "Human C-reactive protein inhibits neutrophil chemotaxis in vitro: possible implications for the adult respiratory distress syndrome," Journal of Laboratory and Clinical Medicine, vol. 115, no. 3, pp. 339-345, 1990.

[34] R. M. Heuertz, C. A. Piquette, and R. O. Webster, "Rabbits with elevated serum C-reactive protein exhibit diminished neutrophil infiltration and vascular permeability in C5a-induced alveolitis," American Journal of Pathology, vol. 142, no. 1, pp. 319328, 1993.

[35] N. Ahmed, R. Thorley, D. Xia, D. Samols, and R. O. Webster, "Transgenic mice expressing rabbit C-reactive protein exhibit diminished chemotactic factor-induced alveolitis," American Journal of Respiratory and Critical Care Medicine, vol. 153, no. 3, pp. 1141-1147, 1996.

[36] A. J. Szalai, A. Agrawal, T. J. Greenhough, and J. E. Volanakis, "C-reactive protein. Structural biology, gene expression, and host defense function," Immunologic Research, vol. 16, no. 2, pp. 127-136, 1997.

[37] C. Zouki, M. Beauchamp, C. Baron, and J. G. Filep, "Prevention of in vitro neutrophil adhesion to endothelial cells through shedding of L-selectin by C-reactive protein and peptides derived from C- reactive protein," Journal of Clinical Investigation, vol. 100, no. 3, pp. 522-529, 1997.

[38] M. Yamamoto, K. Yoshizaki, T. Kishimoto, and H. Ito, "IL-6 is required for the development of Th1 cell-mediated murine colitis," Journal of Immunology, vol. 164, no. 9, pp. 4878-4882, 2000.

[39] Z. Xing, J. Gauldie, G. Cox et al., "IL-6 is an antiinflammatory cytokine required for controlling local or systemic acute inflammatory responses," Journal of Clinical Investigation, vol. 101, no. 2, pp. 311-320, 1998. 
[40] J. van Snick, "Interleukin-6: an overview," Annual Review of Immunology, vol. 8, pp. 253-278, 1990.

[41] A. Vink, C. Uyttenhove, P. Wauters, and J. van Snick, "Accessory factors involved in murine $\mathrm{T}$ cell activation. Distinct roles of interleukin 6, interleukin 1 and tumor necrosis factor," European Journal of Immunology, vol. 20, no. 1, pp. 1-6, 1990.

[42] P. H. Canter, B. Wider, and E. Ernst, "The antioxidant vitamins A, C, E and selenium in the treatment of arthritis: a systematic review of randomized clinical trials," Rheumatology, vol. 46, no. 8, pp. 1223-1233, 2007. 


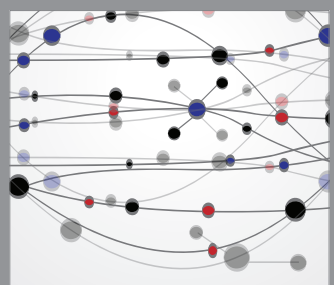

The Scientific World Journal
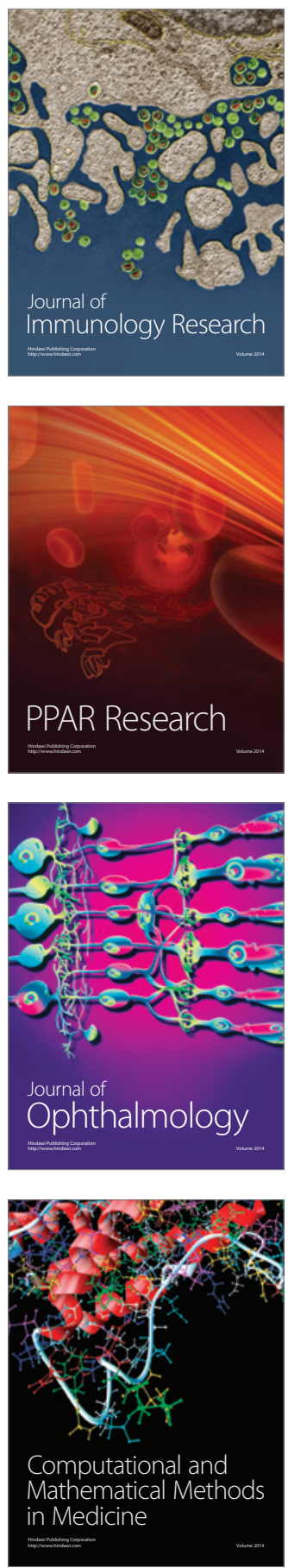

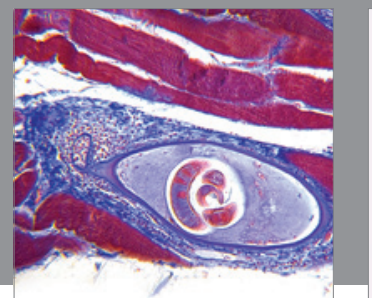

Gastroenterology

Research and Practice
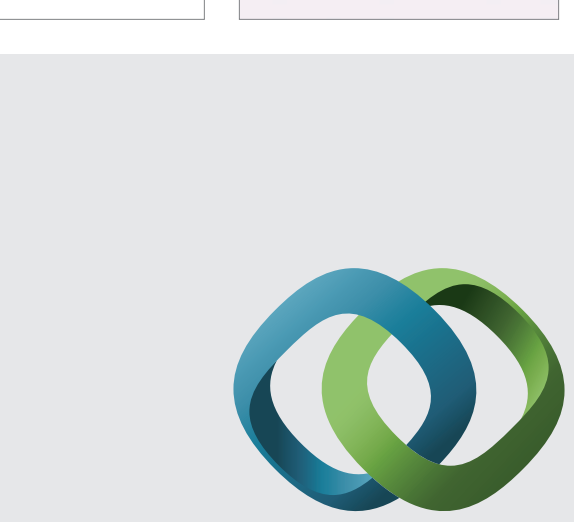

\section{Hindawi}

Submit your manuscripts at

http://www.hindawi.com
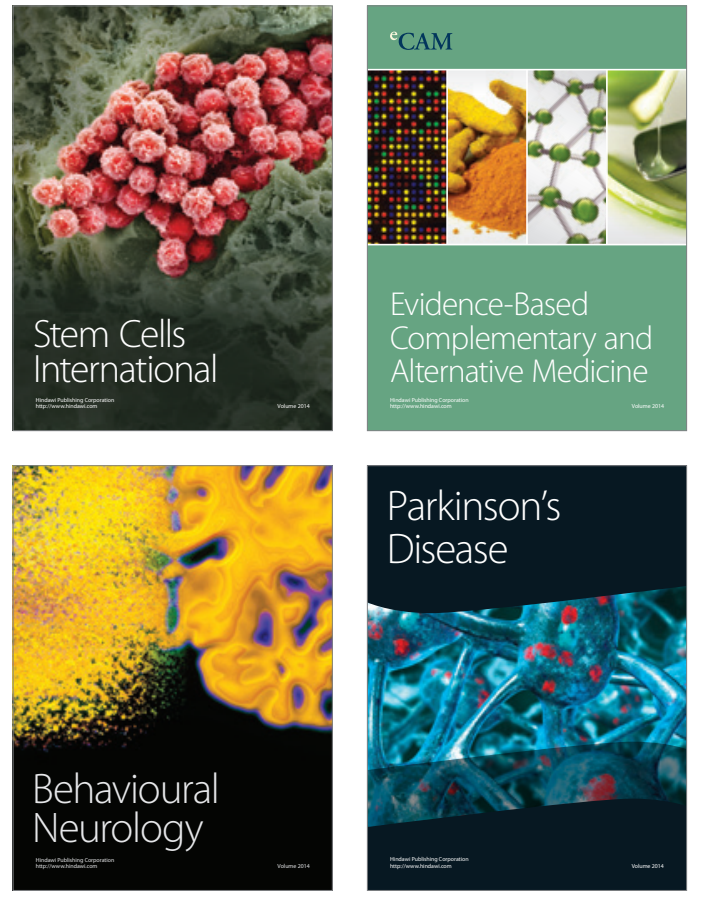
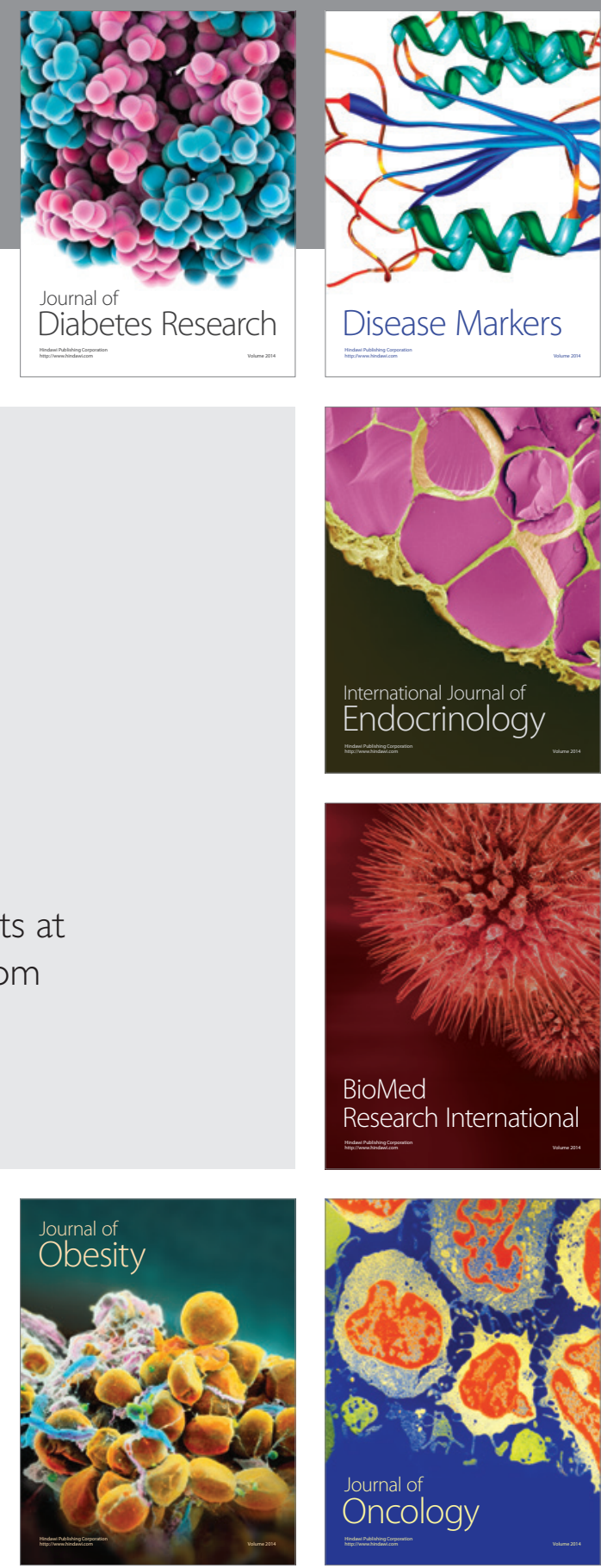

Disease Markers
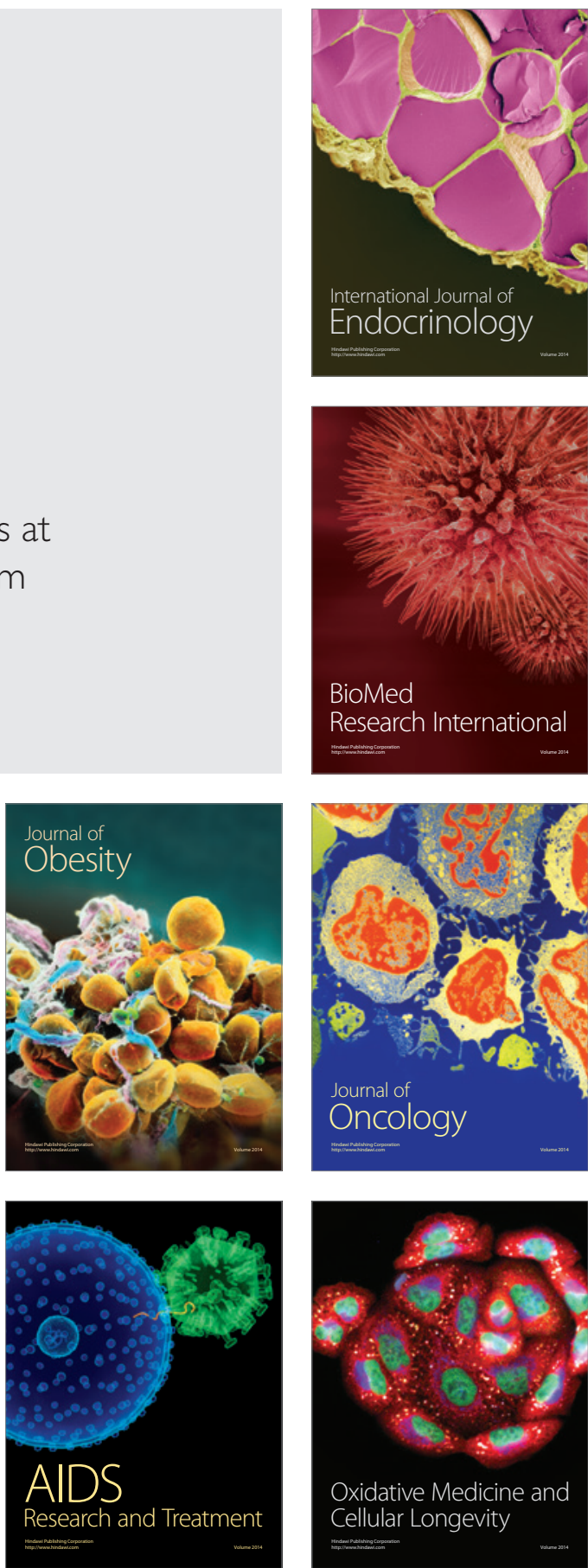